\title{
DO REALISMO INGÊNUO À INGENUIDADE PERIGOSA: CRISE E TELEOLOGIA DA HUMANIDADE EUROPEIA EM HUSSERL
}

From ingenuous realism to dangerous ingenuousness: the European crisis and teleology according to Husserl

Carlos Diógenes C. Tourinho *

Resumo: O presente artigo aborda a crítica de Husserl à doutrina do naturalismo. Relaciona a referida crítica nas origens da fenomenologia com o período das reflexões sobre a crise do homem europeu. Mais precisamente, 0 artigo investiga a hipótese de que haveria uma inseparabilidade entre o realismo filosoficamente ingênuo das ciências positivas (adotado pelas ciências naturais, bem como pelas ciências humanas) e a ingenuidade perigosa de tais ciências (cujos reflexos se fazem notar na formação da humanidade europeia, na primeira metade do século XX). Tal hipótese nos permitiria, enfim, elucidar o ímpeto da crítica de Husserl ao naturalismo, revelando-nos a ideia de uma "teleologia oculta" da referida humanidade.

Palavras-chaves: Edmund Husserl, Crítica, Naturalismo, Crise, Cultura, Teleologia,

Abstract: This paper discusses Husserl's critique of the doctrine of naturalism, linking this critique of the origins of phenomenology to the period of reflection on the European crisis. More specifically, this paper investigates the hypothesis of an inseparability between the philosophically ingenuous realism of the positive sciences (adopted by the natural sciences as well as by the human

* Doutor em Filosofia pela PUC-Rio. Professor Associado do Departamento de Filosofia e do Programa de Pós-Graduação em Filosofia da Universidade Federal Fluminense (UFF/ Niterói-RJ, Brasil). Artigo recebido em 05/02/2018 e aprovado para publicação em 22/11/2018. 
sciences) and the dangerous ingenuousness of such sciences (whose effects can be observed in the shaping of European humanity, during the first half of the 20th century). Such a hypothesis would enable us to investigate the impetus of Husserl's criticism of naturalism that manifests the idea of a "hidden teleology" of the European humanity.

Key-words: Edmund Husserl, Criticism, Naturalism, Crisis, Culture, Teleology.

\section{Introdução}

$\mathrm{U}$ m olhar sobre o caminho traçado por Edmund Husserl na primeira metade do século XX permite-nos notar o quão relevante se torna a crítica do autor à doutrina naturalista (para a qual pensar o mundo consiste em pensá-lo tão somente como uma realidade de fatos naturais), seja nas origens da fenomenologia (no âmbito dos debates sobre a fundamentação da Lógica), seja no período tardio (no qual se intensificam as reflexões sobre a crise da Europa). Tal relevância leva-nos a perguntar: até que ponto a intenção que move a crítica de Husserl ao naturalismo nos permite passar, sem prejuízo do sentido que lhe é próprio, de um debate epistêmico sobre os contrassensos teóricos inerentes às tentativas de fundar as ciências no naturalismo para um conjunto de reflexões sobre a crise da cultura europeia? O presente artigo pretende analisar tal questão, chamando-nos a atenção para a crítica de Husserl ao projeto de fundamentação das ciências no naturalismo, bem como para as denúncias que se intensificam na década de 30 (ainda que fortemente antecipadas desde o começo dos anos vinte) sobre os impactos produzidos pela doutrina naturalista na formação do homem europeu, com graves consequências para a cultura europeia. $\mathrm{O}$ artigo convida-nos, mais precisamente, daí a formulação do seu título, a investigar a hipótese segundo a qual haveria uma inseparabilidade entre o realismo filosoficamente ingênuo das ciências positivas (assumido, no último quarto do século XIX, pelas ciências naturais, bem como pelas ciências humanas, dentre as quais destacamos a própria Psicologia) e a ingenuidade perigosa de tais ciências (cujos reflexos se fazem notar na mentalidade do homem europeu do período Entre Guerras). Tratar-se-ia, em suma, de investigar tais momentos do itinerário husserliano como duas "pontas da mesma corda", na qual a primeira delas converte-se na segunda, sem perder de vista o sentido que a impulsiona: denunciar os contrassensos do relativismo cético, inerentes à doutrina naturalista, bem como a ameaça que a aceitação de tal doutrina representaria para a própria filosofia. Tal hipótese nos permitiria elucidar o alcance da crítica de Husserl ao naturalismo, revelando-nos, por fim, na década de 30, a ideia de uma "teleologia oculta" à humanidade europeia, cuja análise nos leva a uma teleologia mais originária da própria intencionalidade, conforme 
veremos na conclusão do presente artigo. Examinemos, então, a "primeira ponta" desta corda.

\section{A critica de Husserl ao naturalismo no começo do século $X X$}

Ao examinar o percurso de Husserl ainda nas origens da fenomenologia, notamos uma preocupação renovada do autor em afirmar a tese segundo a qual toda tentativa de fundamentação da Matemática, da Lógica, ou mesmo, da própria Filosofia, em um pensamento que tenha como base a doutrina do naturalismo (para a qual o mundo equivaleria a uma realidade de fatos naturais), se torna uma tentativa que nos conduz, inevitavelmente, a um "contrassenso teórico" (pois confunde os domínios do real e do ideal) e, por conseguinte, a um ceticismo que se autocontradiz. Afinal de contas, como nos mostra Husserl desde 1900, em Prolegômenos à lógica pura ("Prolegomena zur reinen Logik"), volume propedêutico das Investigações Lógicas (Logische Untersuchungen), ao ignorar a distinção entre o ato psicológico de pensar (Denken) e o conteúdo ideal do pensamento (Gedanke), reduzindo, indevidamente, tal conteúdo a uma realidade de fatos naturais, aspirando algo como uma "física do pensar" (Physik des Denkens), para usar os termos de Theodor Lipps ${ }^{1}$, além de incorrer em problemas de fundamentos, o modo de consideração natural (no qual se apoia a Psicologia como uma ciência positiva) confina o homem - enquanto ente psicofísico - a uma relação meramente empírica com o mundo. Neste caso, em tal modo de consideração, por mais êxito que o pensamento obtenha, fica confinado a inferir, a partir da observação dos fatos, proposições que não são senão, como nos diz Husserl, no $\S 21$ de Prolegômenos, "generalizações vagas da experiência" (vage Verallgemeinerungen der Erfahrung) ${ }^{2}$ que, como tais, não perdem o seu cariz episódico, não nos livrando, por conseguinte, do assédio da dúvida e do que insiste em não se mostrar evidentemente como tal. Tais proposições inferidas da experiência nos levariam, inevitavelmente, segundo Husserl, uma vez que as mesmas careceriam de validade apodítica, a um domínio de contingências. Afinal, como o próprio autor nos lembra, no $\S 36$ de Prolegômenos: "de fatos só se pode derivar novamente fatos" ("aus Tatsachen lassen sich immer wieder nur Tatsachen ableiten") 3.

\footnotetext{
${ }^{1}$ Lipps afirma-nos que a lógica é uma física do pensar ou ela não é nada ("Die Logik ist dann auch nach dieser Aufassung ihrer Aufgabe Physik des Denkens oder sie ist überhaupt nichts"). Cf. LIPPS, T "Die Aufgabe der Erkenntnistheorie und die Wundt'sche Logik". In: Philosophische Monatshefte, v. 16, 1880, p. 531.

${ }^{2}$ HUSSERL, E. Logische Untersuchungen. Erster Band. "Prolegomena zur reinen Logik". Halle a. d. S.: Max Niemeyer, ([1900] 1913), § 21, p. 61.

${ }^{3}$ Idem, § 36, p. 119. Pouco tempo depois da publicação de Prolegômenos, nas lições de 1902/1903, Husserl afirma-nos: "Nós não extraímos necessidades e universalidades da experiência, que
} 
Se afirmarmos, em conformidade com o pensamento natural, a tese segundo a qual "todas" as proposições inferidas pelo pensamento consistem, ou se fundam (em última instância), em generalizações da experiência e, por isso, na medida em que carecem de validade absoluta, são proposições passíveis de dúvida, estaremos supondo, ao menos, que a própria tese afirmada é uma "exceção" à regra. Do contrário, ela própria seria também o resultado de uma inferência da experiência, consistindo, portanto, em uma generalização empírica que, como tal, é contingente. Inviabiliza-se, com a referida tese, a apreensão intelectiva de conteúdos de pensamento que tenham valor absoluto e que assegurem uma "ausência absoluta de dúvidas" (absolute Zeifellosigkeit), mantendo, com isso, as portas abertas para um relativismo. A crítica da razão teórica exercida sobre a tese naturalista denuncia-nos, como dirá Husserl, nas lições de 1902/1903, publicadas sob o título de Teoria Geral do Conhecimento (Allgemeine Erkenntnistheorie - Vorlesung 1902/03), um relativismo cético que se autocontradiz. Trata-se, portanto, de uma tese na qual notamos "no ceticismo, a razão em contradição consigo mesma" ("In der Skepsis tritt die Vernunft in Widerstreit mit sich selbst")4. Eis o que permanece desconhecido pelas ciências positivas da natureza: o contrassenso a que nos conduz o ceticismo inerente ao pensamento natural adotado por tais ciências. Se considerarmos, ao menos, o período de 1900 a 1911, notaremos o empenho de Husserl em denunciar tal contrassenso.

Tomado pelo anseio incansável de reeditar, no século XX, o projeto de fundamentação da filosofia como uma "ciência rigorosa" (strenge Wissenschaft) - intenção primária que acompanha e move o itinerário husserliano por quase quatro décadas, como lembra Alexandre F. Morujão ${ }^{5}$ - Husserl não poupa esforços em chamar a atenção do leitor para os riscos de fundamentar a filosofia em um naturalismo, esvaindo-a em uma realidade de fatos naturais. Mais do que nunca, tal preocupação visa, primeiramente, denunciar o contrassenso teórico a que tal propósito nos conduz, almejando, assim, afastar o projeto de fundamentação da filosofia de um caminho que incorresse na naturalização do pensamento. Eis uma preocupação que se renova em Husserl, ao longo da primeira década do século $X X$, período no qual vigora um ideal positivista de ciência, cujas bases repousam, como uma espécie de "solo" das ciências positivas, justamente na doutrina do naturalismo.

Mas, se durante o referido período, é devido a problemas de fundamentos que Husserl é levado a denunciar o contrassenso teórico inerente às

\footnotetext{
o somatório de fatos individuais não pode nos dar" ("wir gewinnen nicht Notwendigkeit und Allgemeinheit, die Erfahrung, Summierung von Einzeltatsachen nicht geben kann"). (HUSSERL, E. Allgemeine Erkenntnistheorie - Vorlesung 1902/03. Husserliana: Materialien (Band III). Dordrecht, Netherlands: Springer-Science + Business Media, BV ([1902/1903] 2001), p. 84.

${ }^{4}$ HUSSERL, E. Allgemeine Erkenntnistheorie, op. cit., p. 85.

${ }^{5}$ Cf. MORUJÃO, A. F. "Husserl e a filosofia como ciência rigorosa". In: MORUJÃO, A. F. Estudos Filosóficos, vol. I. Lisboa: Imprensa Nacional - Casa da Moeda, p. 147.
} 
iniciativas psicologistas de se tomar o conteúdo ideal do pensamento em termos de uma realidade psicofísica, fazendo da Psicologia uma espécie de "filosofia primeira", conforme destaca Emmanuel Housset ${ }^{6}$, a partir deste período, cada vez mais, nota-se uma preocupação por parte do autor em denunciar os riscos que a realização de tal iniciativa naturalista teria para a formação do homem europeu. Ainda em caráter embrionário, o primeiro sinal desta nova preocupação já pode ser notado em "A filosofia como ciência de rigor" (Philosophie als strenge Wissenschaft), artigo publicado em 1911 para o primeiro número da Revista Logos, no qual Husserl nos chama a atenção para os perigos do naturalismo para a cultura. Deparamo-nos com os reflexos de uma crítica anunciada dez anos antes em Prolegômenos. Porém, se num primeiro momento, tal crítica concentrava-se nos problemas de se buscar uma fundamentação da Lógica na Psicologia, a partir de 1911, a crítica ao naturalismo ampliava-se para o domínio das reflexões sobre a cultura.

Já no começo da primeira parte do referido artigo, intitulada "Filosofia Naturalística" (Naturalistische Philosophie), Husserl afirma-nos que: “...o cientista dedicado às ciências naturais tende a considerar tudo como natural..." ${ }^{7}$, mantendo firme a sua crença de que não se depara senão com a natureza, a começar com a natureza física. O autor nos diz que, para o naturalista: "Tudo o que é, ou é propriamente físico...ou se for psíquico, é mera variação dependente do físico..." ${ }^{8}$. Para Husserl, em sua forma extrema, o naturalismo resulta, então, por um lado, em uma "naturalização da consciência" (Naturalisierung des Bewußtseins), incluindo todos os dados intencionais e imanentes da consciência e, por outro lado, em uma "naturalização das ideias" (Naturalisierung des Ideen), e de todos os ideais e normas absolutos. Conforme Husserl já apontava desde 1896, ainda no período de Halle, o naturalismo considera todos os princípios lógicos, as chamadas "leis do pensamento" (Gesetze des Denkens), em termos de leis naturais do pensamento (incorrendo, com isso, no contrassenso de confundir o juízo como ato psicológico de pensar com o juízo como unidade ideal da lógica). Tal como Husserl já havia também denunciado, nas lições de 1906 e 1907, o contrassenso cético resultante

\footnotetext{
${ }^{6}$ Cf. HOUSSET, E. Husserl et l'énigme du monde. Paris: Éditions du Seuil, 2000, p. 29.

7 HUSSERL, E. Philosophie als strenge Wissenschaft. In: Logos: Zeitschrift für systematische. Philosophie, 1910-1911, p. 294.

${ }^{8}$ Ibid., p. 294. Dentre os adeptos do naturalismo citados por Husserl, deparamo-nos com o nome de Ernst Haeckel (1834-1919), biólogo e naturalista alemão. Em Der Monismus (1893), Haeckel defende uma "filosofia monista da natureza" (monistische Naturphilosophie). O autor afirma-nos, a propósito das considerações de Schlesinger: “...estou plenamente de acordo com a sua concepção unitária da natureza inteira, que designamos com o único nome de Monismo...insistimos na unidade fundamental da natureza orgânica e inorgânica". Acrescenta ainda: "toda atividade psíquica do homem, e mesmo a sua consciência, derivam de uma mesma origem, como funções do sistema nervoso central e, do ponto de vista monista, devem ser submetidos ao mesmo raciocínio". (HAECKEL, E. Der Monismus als Band zwischen Religion und Wissenschaft. Bonn: Verlag von Emil Strauss, 1893, p. 9-23).
} 
do modo de consideração naturalista manter-se-ia "obscuro" para o próprio cientista natural (de viés positivista), uma vez que ele mesmo não se aperceberia do caráter infundado de sua posição. Nos termos de Husserl: “O contrassenso que se encontra nele não é manifesto, mas se oculta a ele próprio..." ${ }^{\prime 9}$. Alguns anos antes do famoso artigo de 1911, no Apêndice A, VIII, do $\S 33$ das lições de 1906/1907, publicadas sob o título de Introdução à Lógica e Teoria do Conhecimento (Einleitung in die Logik und Erkenntnistheorie - Vorlesungen 1906/07), Husserl chamaria este ceticismo não declarado de "inconsciente" (unbewusster Skeptizismus) ${ }^{10}$, chegando mesmo a compará-lo ao "verme" da dúvida ou obscuridade (der Wurm des Zweifels oder der Unklarheit), inapercebido em todo conhecimento dito "positivo", dado como "definitivo" (bestimmten) ${ }^{11}$. Tal ceticismo inconsciente vai, aos poucos, corroendo e destruindo a tomada de posição ingênua assumida pelas ciências da natureza que, conforme avançam, ignoram, por completo, os problemas relacionados à possibilidade do conhecimento, assumindo, com isso, um realismo filosoficamente ingênuo, uma vez que o mesmo não se interroga pelo sentido da existência, bem como da objetividade, do mundo que tais ciências consideram, acriticamente, como dadas.

Para Husserl, se o naturalista tende a considerar os argumentos que apontam para o contrassenso inerente à sua posição como argumentos meramente "escolásticos", ele o faz na medida em que, do ponto de vista filosófico, nos diz Husserl: "Toda ciência natural é ingênua pelos seus pontos de partida"12. Se até então, para Husserl, esta "cegueira naturalista" estaria relacionada ao que impede o adepto do pensamento natural de notar os problemas de fundamentos nos quais a sua posição incorre, já a partir do artigo de 1911, o autor começa a chamar a atenção para os perigos desta dita ingenuidade, afirmando-nos que: “...os contrassensos teóricos são inevitavelmente seguidos por contrassensos (discordâncias evidentes) no procedimento atual, teórico, axiológico, ético"13. Em seguida, nos diz: "O Naturalista é doutrinador, pregador, moralizador, reformador"14.

\footnotetext{
${ }^{9}$ HUSSERL, E. Philosophie als strenge Wissenschaft. In: Logos: Zeitschrift für systematische. Philosophie, 1910-1911, p. 295-296.

${ }^{10}$ Husserl emprega este termo desde as lições de 1902/1903, afirmando-nos que: "Quase todas as teorias do conhecimento falsas contêm um ceticismo inconsciente..." ("Fast jede falsche Erkenntnistheorie ist unbewusster Skeptizismus".) (HUSSERL, E. Allgemeine Erkenntnistheorie Vorlesung 1902/03, p. 87).

${ }^{11}$ Cf. HUSSERL, E. Einleitung in die Logik und Erkenntnistheorie - Vorlesungen 1906/07. Husserliana (Band XXIV). Dordrecht, The Netherlands: Martinus Nijhoff, ([1906/1907] 1984), Apêndice A, VIII, do § 33, p. 367.

${ }_{12}$ HUSSERL, E. Philosophie als strenge Wissenschaft. In: Logos: Zeitschrift für systematische. Philosophie, 1910-1911, p. 298.

${ }^{13}$ HUSSERL, E. Philosophie als strenge Wissenschaft. In: Logos: Zeitschrift für systematische. Philosophie, 1910-1911, p. 295.

${ }^{14}$ Ibid., p. 295.
} 
Husserl afirma-nos ainda, ao final da introdução do artigo de 1911, que o naturalismo dominante na Europa: “...significa praticamente um perigo crescente para a nossa cultura" ${ }^{\prime 15}$. Se em tal artigo, tais observações não têm maiores desdobramentos, elas já indicam, por si só, uma nova preocupação do autor: além dos problemas de fundamentos nos quais o naturalismo incorre, caberá também alertar para os impactos que tal modo de consideração teria para a formação da mentalidade do homem europeu. É como se Husserl já antevisse, três anos antes da primeira Grande Guerra, a possibilidade crescente de que a ingenuidade filosófica (aparentemente inofensiva) do realismo assumido pelas ciências positivas pudesse se converter em uma ingenuidade perigosa para a cultura e, portanto, em um realismo fatídico e sem ideais, por meio do qual a humanidade europeia ficaria circunscrita às suas próprias acidentalidades, abrindo, novamente, as portas para um relativismo cético. Vejamos, então, a partir de agora, a "outra ponta da corda".

\section{A critica de Husserl ao naturalismo nas reflexões sobre a crise da Europa}

Mas é somente a partir da década de 20 que se evidencia a preocupação de Husserl em dar seu parecer a respeito da crise da Europa, propondo-nos, ao mesmo tempo, uma reforma racional da cultura que pudesse, em meio à crise, conduzir a humanidade europeia em direção ao que ele próprio considera uma "humanitas autêntica" (echter Humanität), inviabilizada por preconceitos naturalistas (naturalistische Vorurteile). Husserl afirma-nos, logo no primeiro dos seus artigos publicados pela revista japonesa Kaizo (palavra cujo significado é justamente o de "renovação"), intitulado "Renovação. Seu problema e seu método" ("Erneuerung. Ihr Problem und ihre Methode"), de 1923, que a Europa está em crise e, em seu doloroso presente, uma renovação se faz necessária em meio ao cenário devastador deixado pela Primeira Guerra. Trata-se, aqui, poder-se-ia dizer, nos termos de Pedro Alves, de uma "renovação" e não de uma "inovação"16. Afinal, essa renovação não é uma reinvenção, mas, para Husserl, trata-se do restabelecimento contínuo de algo no qual radica o sentido autêntico desta humanidade. Tratar-se-ia, então, de criar condições para a retomada da realização de uma racionalidade efetiva (cuja aspiração consiste em afirmar ideias e ideais absolutos, válidos incondicionalmente, independente de quaisquer acidentalidades), viabilizando, com isso, nos termos

\footnotetext{
${ }^{15}$ Ibid., p. 293.

${ }^{16}$ Cf. ALVES, P. M. S. "Introdução na tradução portuguesa". In: HUSSERL, E. Europa: Crise e Renovação. Rio de Janeiro: Forense Universitária, 2014, p. X.
} 
de Husserl, uma educação universal que pudesse recolocar a humanidade no caminho da veracidade ${ }^{17}$.

Essa mesma humanidade que se orgulhava do ideário positivista de ciência desde o último quarto do século XIX e, por conseguinte, de ter alcançado um estágio positivo, supostamente "mais avançado" numa linha progressiva, começava a dar sinais de declínio a partir da Primeira Guerra, revelando, de acordo Husserl, a sua ausência de sentido (sua "indescritível miséria, não somente moral e religiosa, senão filosófica" $)^{18}$. E como dirá Husserl pouco mais de uma década após o artigo de 1923, no $\S 5$ de A Crise das Ciências Europeias e a Fenomenologia Transcendental (Die Krisis der europäischen Wissenschaften und die transzendentale Phänomenologie), último grande testemunho do autor sobre os contrassensos produzidos pelo naturalismo: perder a crença na capacidade do homem de prover ao seu mundo circundante, bem como à sua existência individual e geral um sentido racional implica em perder a crença "em si mesmo"19. Sobre a crise vivida por essa humanidade, o autor nos dizia, desde o artigo de 1923: "Se ela já tinha se tornado vacilante antes da guerra, desmoronou-se agora completamente" ${ }^{20}$. Daí a formulação husserliana da questão, em tom de manifesto: a humanidade europeia estaria, com a guerra, condenada a se desorientar por um pessimismo fatídico e por um realismo, outrora apenas ingênuo e agora sem ideais? Husserl pergunta-nos, então: a racionalidade efetiva e a excelência (de nos colocarmos acima de nossas preocupações e infortúnios individuais, religando-nos às questões supremas da humanidade) não seria um caminho possível para remediar essa crise? Certamente, se esta crise não fosse marcada por uma perda da crença em tal racionalidade e excelência. Se por um lado, a ideia de uma reforma da cultura implica, ao menos, tal como Husserl a pensa, na retomada desta

\footnotetext{
${ }^{17}$ Em carta escrita a Winthrop Bell (11-08-1920), Husserl afirmava: Para uma "renovação ético-política" da humanidade, faz-se necessário "uma arte da educação universal da humanidade, que esteja sustentada pelos mais altos ideais éticos, claramente fixados; uma arte em forma de uma poderosa organização literária para ilustrar a humanidade e educá-la, conduzindo-a no caminho da veracidade". Carta citada por Guillermo Hoyos Vásquez. (Cf. VÁSQUEZ, G. H. "La Ética Fenomenológica como Responsabilidad para la Renovación Cultural". In: Renovación del hombre y de la cultura: Cinco Ensayos / Edmund Husserl. Barcelona: Anthropos Editorial, 2012, p. VIII).

${ }^{18}$ Em outra carta da mesma época, escrita a William Hocking (03-07-1923), Husserl afirma que: "O que tem sido posto descoberto pela guerra é a indescritível miséria, não somente moral e religiosa, senão filosófica da humanidade". Citada por Guillermo Hoyos Vásquez. (Cf. Idem, op. cit. p. VIII).

19 "Se o homem perde essa crença, isso não significa nada mais senão que: ele perde a crença em si próprio" "Verliert der Mensch diesen Glauben, so heißt das nichts anderes als: er verliert den Glauben 'an sich selbst'..."). (Husserl, E. Die Krisis der europäischen Wissenschaften und die transzendentale Phänomenologie. Husserliana. Band VI. Netherlands: Martinus Nijhoff, ([1936] 1976), § 5, p. 11).

${ }^{20}$ HUSSERL, E. "Erneuerung. Ihr Problem und ihre Methode (1923)". In: Aufsätze und Vorträge (1922-1937). Husserliana. Band XXVII. Dordrecht / Boston / London: Kluwer Academic Publishers, ([1923] 1989), p. 4.
} 
crença, por outro lado, o principal obstáculo a ser superado se encontra na figura dos homens que, absorvidos pela visão pessimista, não hesitam em considerar tal retomada - tanto no plano individual quanto em nível social e cultural - como um "objetivo quimérico" (chimärisches Ziel). Contra a visão pessimista segundo a qual a humanidade seria reduzida a uma "humanidade de fatos", Husserl aposta suas fichas em uma reforma racional da cultura, por meio da qual reacenderíamos: "A crença que nos preenche - que à nossa cultura não é permitido se dar por satisfeita, que ela pode e deve se tornar reformada através da razão e da vontade humanas..." ${ }^{21}$. Como se o restabelecimento dessa crença fosse, para usar um termo das Investigações Lógicas, um "preenchimento de significação" (Bedeutungserfüllung) da cultura, sem o qual esta humanidade - tomada por seus preconceitos naturalistas - permaneceria em um estado de desamparo em meio ao cenário do Entre Guerras.

A aspiração por uma reforma racional da cultura deveria abrir os caminhos obstruídos por tais preconceitos. Por esse motivo, tal reforma aspiraria, antes de tudo, reformar a cultura fática que confina, através de uma doutrinação (como alertava Husserl desde o artigo de 1911), os homens a juízos dirigidos para simples fatos de existência, nos quais somente se admitiria como válido o que fosse objetivamente verificável. Se o caráter reformador do naturalismo é de cunho "doutrinador" e, portanto, não se encontra amparado por fundamentos racionais, em Husserl, deparamo-nos também com uma aspiração reformadora, porém, trata-se, diferentemente, de promover, através de uma crítica da razão, uma reforma radical da filosofia, no sentido de fundá-la como uma "ciência de rigor" que serviria de referência para as demais ciências, elevando-a, assim, ao "...lugar de realização de uma cultura autêntica, articulada nos planos da vida cognitiva, ética e social" 22 . Somente superando tais preconceitos naturalistas, essa humanidade seria recolocada no caminho de uma racionalidade, unindo os indivíduos para além de uma condição meramente acidental.

Em maio de 1935, Husserl manifesta-se novamente sobre a crise da Europa, ao proferir a famosa conferência de Viena, intitulada A crise da humanidade europeia e a filosofia ("Die Krisis des europäischen Menschentums und die Philosophie"). Nela, Husserl apresenta-nos um diagnóstico da crise vivida pelo homem europeu, ao elucidar a etiologia da sua enfermidade espiritual, reivindicando, em tom de manifesto, o reestabelecimento do que remediaria tal enfermidade. A consolidação do projeto de naturalização da "vida do espírito" fomentou, na formação da mentalidade europeia, um esquecimento daquilo que nos remeteria à "estrutura espiritual" (geistige Gestalt)

${ }^{21}$ HUSSERL, E. “Erneuerung. Ihr Problem und ihre Methode (1923)". In: Aufsätze und Vorträge (1922-1937). Husserliana. Band XXVII. Dordrecht / Boston / London: Kluwer Academic Publishers, ([1923] 1989), p. 5.

${ }^{22}$ Cf. ALVES, P. M. S. "Introdução na tradução portuguesa". In: HUSSERL, E. Europa: Crise e Renovação. Rio de Janeiro: Forense Universitária, 2014, p. X. 
da Europa, a saber: o surgimento da filosofia, enquanto uma nova forma cultural, na qual todas as ciências sistemáticas estariam incluídas enquanto suas ramificações. Esta nova forma cultural conduz os homens, por meio de um "novo tipo de posição" (neuartige Einstellung), a um deslocamento do olhar de suas metas finitas e circunstanciais, próprias de suas preocupações diárias inerentes a um "mundo circundante" (Umwelt), para metas infinitas, transformando-os, assim, na figura de um novo homem cuja reflexão - dada a radicalidade de elevá-lo acima de sua própria individualidade - faz dele uma espécie de "espectador desinteressado" (uninteressierter Zuschauer), preocupado tão somente em ver e descrever adequadamente (sehen und adäquat zu beschreiben), conforme Husserl aponta no $\S 15$ de Meditações Cartesianas (Cartesianische Meditationen), em 193123. Trata-se da decisão deste novo homem de consagrar toda a sua vida futura à teoria, de dar a ela um caráter universal. Decisão essa, cujos efeitos se fazem, rapidamente, notar, em relações de convivência comunitária, através da propagação do exercício do espírito crítico entre os homens. Tais efeitos espirituais cresceriam, segundo Husserl, não apenas no interior do círculo de filósofos, mas também em um movimento dedicado à educação (ao alcançar homens que, mesmo em outras profissões, se voltariam atentos para tal exercício tão peculiar). Seja como for, a nova posição destaca-se pela "universalidade da postura crítica" (Universalität der kritischen Haltung), gerando repercussões de grande alcance em toda a vida cultural, tal como salienta o autor, na primeira parte da referida conferência de $1935^{24}$.

É como se Husserl nos propusesse, no âmbito das reflexões sobre a cultura, um exercício fenomenológico a respeito do fenômeno "Europa", elucidando, através de um retorno ao que há nele de mais originário, o seu sentido primordial. Revela-se, então, por uma espécie de "autorreflexão" (Selbstbesinnung), o que Husserl identifica como o "sentido espiritual" (geistiger Sinn) da Europa: o surgimento da filosofia, de uma nova posição perante o mundo e, por conseguinte, de um novo homem. Trata-se, portanto, não de uma simples justaposição geográfica e cultural das diferentes nações, mas daquilo que, segundo Husserl, guiaria e uniria essa humanidade para além de suas diferenças culturais. Tal exercício fenomenológico revela-nos, como nos diz Husserl no § 7 de A Crise das Ciências Europeias, uma "teleologia oculta" (verborgene Teleologie), responsável pela saúde espiritual do homem europeu ${ }^{25}$. Tais metas infinitas contempladas por este novo homem seriam, portanto, segundo Husserl, tal como um telos espiritual a guiar esta nova humanidade, conferindo-lhe o sentido de uma evolução em direção a um polo eterno. Trata-se, portanto, não

\footnotetext{
${ }^{23}$ Cf. HUSSERL, E. Cartesianische Meditationen und Pariser Vorträge. Husserliana (Band I). Den Haag, Netherlands: Martinuos Nijhoff, ([1931/ 1929] 1973), § 15, p. 73.

${ }^{24}$ Cf. HUSSERL, E. "Die Krisis des europäischen Menschentums und die Philosophie". In: Die Krisis der europäischen Wissenschaften und die transzendentale Phänomenologie. Husserliana. Band VI. Netherlands: Martinus Nijhoff, ([1935] 1976), p. 333.

${ }^{25}$ Cf. HUSSERL, E. Die Krisis der europäischen Wissenschaften und die transzendentale Phänomenologie. Husserliana. Band VI. Netherlands: Martinus Nijhoff, ([1936] 1976), § 7, p. 16.
} 
de uma evolução biológica, mas de uma evolução espiritual por intermédio da qual o conjunto da humanidade europeia se unificaria pelo novo espírito crítico orientado para tais metas infinitas. Aos olhos de Husserl, esta nova posição perante o mundo tornar-se-ia "inata" ("eingeborenen") à Europa, assumindo, assim, a função diretriz desta tal humanidade.

Para Husserl, se esta humanidade mergulhou em uma profunda crise a partir da Primeira Guerra, foi fundamentalmente porque ela própria - ao exaltar o conhecimento matemático da natureza e do mundo em geral, estendendo-o ao conhecimento do espírito, também concebido como "objetivamente no mundo e como tal fundado na corporalidade" 26 - sucumbiu a um esquecimento da própria filosofia. Obsedado pelo êxito galopante das ciências positivas (por sua prosperity), o homem europeu deixou-se tomar por um "...virar as costas indiferente às questões que são as decisivas para uma humanidade genuína" ${ }^{27}$. Tomado pelo orgulho positivista, em uma espécie de "vaidade trágica" 28 , este mesmo homem não percebeu, segundo Husserl, a diferença entre prosperar vigorosamente e degenerar.

A partir da Primeira Guerra, as nações europeias passaram, em um nacionalismo beligerante, a acirrar o ódio e a destruição. Porém, como afirma Husserl, por mais hostilizadas que estejam entre si, tais nações conservam um peculiar parentesco no plano espiritual que as transcende em suas diferenças nacionais. Nos termos de Husserl: “É algo como uma irmandade que nos dá, nesta esfera, uma consciência pátria" (das Bewusstsein einer Heimatlichkeit) ${ }^{29}$. Trata-se, portanto, de um solo espiritual comum - idealizado pela razão filosófica - no qual a humanidade europeia estaria, originariamente, radicada. A perda deste solo espiritual (no sentido de um lhe "dar as costas") implicaria, segundo Husserl, na ruína desta humanidade.

Mas, como Husserl afirmava desde o artigo de 1923, a crise vivida pela Europa resulta da alienação da humanidade europeia a um naturalismo funesto, para o qual o homem não é senão um "fato natural". Segundo Husserl, os próprios cientistas do espírito pouco poderiam auxiliar essa humanidade em meio a este cenário de crise, uma vez que não abdicaram, desde o último quarto do século XIX, de estender, aliando-se ao método experimental das ciências positivas, este mesmo objetivismo para as ciências do espírito, compartilhando com as mesmas, conforme destaca Julien

${ }^{26}$ Cf. HUSSERL, E. "Die Krisis des europäischen Menschentums und die Philosophie". In: Die Krisis der europäischen Wissenschaften und die transzendentale Phänomenologie. Husserliana. Band VI. Netherlands: Martinus Nijhoff, ([1935] 1976), p. 341.

${ }^{27}$ HUSSERL, E. Die Krisis der europäischen Wissenschaften und die transzendentale Phänomenologie. Husserliana. Band VI. Netherlands: Martinus Nijhoff, ([1936] 1976), p. 3-4.

${ }^{28}$ Cf. BANFI, M. A. "Husserl et la crise de la civilization européenne". In: Cahiers de Royaumont, Husserl. Paris: Les Éditions de Minuit, 1959, p. 412.

${ }^{29}$ HUSSERL, E. "Die Krisis des europäischen Menschentums und die Philosophie". In: Die Krisis der europäischen Wissenschaften und die transzendentale Phänomenologie. Husserliana. Band VI. Netherlands: Martinus Nijhoff, ([1935] 1976), p. 320. 
Freund, "a ingenuidade dos pressupostos naturalistas"30. Daí Husserl dizer, na conferência de Viena, o que fora uma das suas principais preocupações ao longo das primeiras décadas do século XX: "É um contrassenso considerar a realidade do espírito como um anexo real dos corpos, atribuindo-lhe um ser espaço temporal dentro da natureza" ${ }^{31}$. A aceitação de tal "objetivismo naturalista" (naturalistische Objektivismus) ${ }^{32}$ implicaria, segundo Husserl, em uma "unilateralidade ingênua" (naive Einseitigkeit): contraditória teoreticamente e perigosa para a cultura. Para Husserl, tal visão naturalista do mundo e do homem, ao relegar à vida espiritual (criadora de formas culturais) um sentido meramente "fisiológico", se tornou a principal responsável por restringir esta humanidade a uma mera acidentalidade.

Para remediar tal estado de adoecimento espiritual, como condição para superar o perigoso divisionismo nacionalista, Husserl não hesita em convocar esta humanidade a reviver o que foi esquecido, fazendo renascer a experiência de uma "racionalidade efetiva" (wirkliche Rationalität) que, ao triunfar sobre o naturalismo, uma vez mais, uniria esta mesma humanidade, "regenerando-a"33, ao reconduzi-la, através do ideal da razão filosófica, ao seu solo espiritual originário. Afinal, como o próprio autor nos diz, os verdadeiros combates do nosso tempo são os combates entre uma humanidade já arruinada pela guerra, reduzida ao solo de suas particularidades, tais como nação, raça e cultura específicas (confinada ao objetivismo positivista de solo naturalista), e outra que ainda resiste e luta pela sua "auto-compreensão" (Selbstverständnis), por uma nova radicação neste solo espiritual originário (mantendo a crença no ideal de

${ }^{30}$ Cf. FREUND, J. Les théories des sciences humaines. Paris: PUF, 1973, p. 140.

${ }^{31}$ HUSSERL, E. "Die Krisis des europäischen Menschentums und die Philosophie". In: Die Krisis der europäischen Wissenschaften und die transzendentale Phänomenologie. Husserliana. Band VI. Netherlands: Martinus Nijhoff, ([1935] 1976), p. 342.

32 A doutrina do naturalismo tornou-se uma espécie de "solo" das ciências positivas. A aceitação de tal doutrina implica, conforme vimos, em um relativismo cético que se autocontradiz. Neste sentido, na medida em que se apoiam na referida doutrina, as ciências positivas carregam consigo, sem que se apercebam, um ceticismo dito "inconsciente" (unbewusster Skeptizismus). A despeito disso, tomadas por sua "cegueira naturalista", tais ciências reduzem o mundo a uma realidade de fatos naturais na qual o homem estaria confinado a relações meramente empíricas. Neste sentido, para as ciências positivas, conhecer não é senão descrever a regularidade dos fatos observados, inferindo, indutivamente, dos mesmos, generalizações empíricas. Acrescenta-se ainda que tais ciências consideram a objetividade do mundo como "dada", isto é, não se perguntam pelo sentido desta objetividade e, com isso, dão as costas para o problema da possibilidade e limite do conhecimento objetivo. Por fim, pode-se dizer que o termo "objetivismo naturalista" (naturalistischer Objektivismus) das ciências positivas possui, em Husserl, ao menos, um duplo aspecto: na medida em que tais ciências se assentam na doutrina naturalista, equiparam o mundo a uma realidade de fatos, não se apercebendo do relativismo cético que carregam consigo; além disso, assumem um realismo filosoficamente ingênuo, pois tal objetivismo somente considera como válido o que é objetivamente verificável num plano empírico, ignorando o problema filosófico da fundamentação da objetividade do mundo.

${ }^{33}$ Cf. GURWITSCH, A. "The Last Work of Edmund Husserl". In: Philosophy and Phenomenological Research, Vol. 16, No. 3. (Março, 1956), p. 383. 
uma philosophia perennis). A aceitação de um solo meramente geográfico, circunscrito a cada uma das nações europeias, abriria novamente as portas para um relativismo cético. Daí o tom alarmante do discurso de Husserl, ao final do $\S 5$ de A Crise das Ciências Europeias: "Nós, homens do presente, que surgimos neste desenvolvimento, encontramo-nos no grande perigo de nos afundarmos no dilúvio cético e, assim, de deixar escapar a nossa verdade própria" 34 . A nova denúncia mostra uma face da crítica de Husserl ao naturalismo, a partir da qual o que se encontra em jogo não consiste em evidenciar tão somente o contrassenso teórico inerente à doutrina naturalista, mas mostrar que a aceitação de tal doutrina reabriria as portas para um relativismo cético, afastando-nos, dessa vez, do que há de mais genuíno no próprio homem (enquanto animal rationale): a atribuição de sentido racional ao mundo e a sua própria existência.

\section{Considerações Finais}

A intenção que move as reflexões de Husserl sobre a crise da humanidade europeia religa-nos, portanto, de certo modo, a uma preocupação que se faz presente nas origens da fenomenologia: denunciar, através de uma crítica da razão, os contrassensos do relativismo cético, inerentes à aceitação da doutrina naturalista. Se na primeira década, tal denúncia concentra-se num âmbito puramente teorético, no período tardio, converte-se em uma preocupação com os impactos que a aceitação de tal doutrina teria para a formação da mentalidade do homem europeu. Afinal, ao dar as costas para tais contrassensos, este homem fomenta uma posição perante o mundo que o leva a ignorar o seu próprio solo espiritual, perdendo de vista“...a ideia que faz dele o que ele é, tornando-o assim alienado de si mesmo" ${ }^{\prime \prime 35}$.

A ingenuidade teorética do objetivismo naturalista converte-se em um realismo fatídico e sem ideais, ampliando o alcance da crítica de Husserl ao naturalismo. Em um mundo reduzido a uma realidade de fatos naturais, esta humanidade não tardaria em justificar suas decisões com base em proposições extraídas dos fatos e, portanto, inferidas a partir da observação positiva dos mesmos. Tais proposições - enquanto generalizações da experiência - não perderiam o seu cariz contingente. O homem europeu estaria, portanto, destinado a um desamparo irreversível, permanecendo, nos termos de Antônio Banfi, “...sem céu, inclinado ao tormento caótico de uma terra inóspita" ${ }^{\prime 36}$, uma vez que, por mais êxito que o pensamento obtivesse, em meio

\footnotetext{
${ }^{34}$ HUSSERL, E. Die Krisis der europäischen Wissenschaften und die transzendentale Phänomenologie. Husserliana. Band VI. Netherlands: Martinus Nijhoff, ([1936] 1976), p. 12.

${ }^{35}$ Cf. GURWITSCH, A. "The Last Work of Edmund Husserl". In: Philosophy and Phenomenological Research, Vol. 16, No. 3. (Março, 1956), p. 382.

${ }^{36}$ BANFI, M. A. "Husserl et la crise de la civilization européenne". In: Cahiers de Royaumont, Husserl. Paris: Les Éditions de Minuit, 1959, p. 426.
} 
à exaltação do objetivismo naturalista (que somente considera como válido o que é objetivamente verificável), o próprio pensar - restrito a inferências de proposições empíricas - não poderia apreender conteúdos cuja validade estivesse inteiramente livre do assédio do que é contingente.

$\mathrm{O}$ enfraquecimento do ideal de uma filosofia universal seria decorrente do estabelecimento de tal sentido homogêneo, próprio da ingenuidade unilateral imposta pela doutrina naturalista. Husserl parece pressentir que a crítica ao naturalismo pode permanecer inaudita por esta humanidade cujo adoecimento espiritual é manifesto. Afinal, como ele próprio nos diz, na mesma conferência de 1935: “...a situação nunca melhorará enquanto não se colocar em evidência a ingenuidade do objetivismo..." ${ }^{37}$ e não nos convencermos do absurdo de considerar a natureza e o espírito como realidades de sentido homogêneo. Trata-se, portanto, de uma "ingenuidade trágica" (dada a sua periculosidade para a própria cultura) e, portanto, distinta daquela mencionada por Husserl a propósito da figura do filósofo como "espectador desinteressado" (uninteressierter Zuschauer). Se a primeira arruína a humanidade, reduzindo-a a uma mera acidentalidade, a segunda a redime do esquecimento de seu telos espiritual.

A denúncia dos perigos do naturalismo para a cultura e, portanto, como Husserl afirma ao final da conferência vienense, do "perigo de todos os perigos" (Gefahr der Gefahren), remete-nos, conforme vimos, para uma enfermidade espiritual, cuja remediação somente poderia se dar por meio de um retorno da humanidade europeia ao seu solo espiritual originário. E é justamente aí que nos deparamos com a ideia de uma "teleologia imanente" à Europa, responsável, aos olhos de Husserl, pela saúde espiritual do homem europeu. Afinal, "...a desordem trágica da vida europeia é caracterizada por sua falta de unidade teleológica" ${ }^{\prime 3}$. Perguntamos, então: quais os "segredos" desta dita teleologia imanente à humanidade europeia?

Uma análise breve de tal teleologia nos faz passar do ideal da razão filosófica de contemplação de metas infinitas para as ciências que, como "regiões espirituais", consistiriam em ramificações, contidas na própria filosofia. Tais regiões teriam, por sua vez, uma teleologia própria que as guiaria: a de pretender realizar, por um esforço contínuo, a ideia diretriz de se constituir como uma "ciência autêntica" (echte Wissenschaft), conforme salienta Husserl, no $\S 4$ de Meditações Cartesianas $^{39}$. Trata-se de uma pretensão (Prätention) que tais ciências trariam consigo, sem que pudessem justificá-la através de sua própria existência enquanto fenômeno de cultura.

\footnotetext{
${ }^{37}$ HUSSERL, E. "Die Krisis des europäischen Menschentums und die Philosophie". In: Die Krisis der europäischen Wissenschaften und die transzendentale Phänomenologie. Husserliana. Band VI. Netherlands: Martinus Nijhoff, ([1935] 1976), p. 345.

${ }^{38}$ Cf. BANFI, M. A. "Husserl et la crise de la civilization européenne". In: Cahiers de Royaumont, Husserl. Paris: Les Éditions de Minuit, 1959, p. 414.

${ }^{39}$ Cf. HUSSERL, E. Cartesianische Meditationen und Pariser Vorträge. Husserliana (Band I). Den Haag, Netherlands: Martinuos Nijhoff, ([1931/ 1929] 1973), § 4, p. 50.
} 
E é justamente nesta pretensão que encontramos a ciência como "ideia de ciência autêntica" (Idee echter Wissenschaft). A atividade científica avança, por aproximações sucessivas, na obtenção do conhecimento, na demonstração de hipóteses. Todavia, se a ciência exerce, de tempos em tempos, a corrigibilidade de suas conjecturas, tal movimento converge, segundo Husserl, para aquilo que as ciências aspiram, em sentido verdadeiro e próprio (im wahren und echten Sinne), como um fim ideal: alcançar verdades "válidas uma vez por todas e para todos" (ein für allemal und für jedermann gültig) ${ }^{40}$. Deste modo, afirma-nos o autor que, a despeito de tal processo de corrigibilidade inerente à atividade científica, nada poderia impedir as ciências de viver ("einzuleben"), por um esforço contínuo, o sentido do que aspiram, preservando uma ideia clara e distinta do fim almejado. As ciências desenvolvem-se, então, inclinadas à busca por maior exatidão e precisão, exibindo um estado corrente de realização, no qual tendem para o alcance de uma perfeição crescente, gradualmente realizada. Neste sentido, a ideia diretriz de se constituir como uma "ciência autêntica" torna-se o terminus que polariza com o esforço científico, orientando-o para o conhecimento.

A análise dos momentos constitutivos desta ideia teleológica geral (allgemeine Zweckidee) das ciências remete-nos para o impulso ao conhecimento que, para Husserl, consiste na liberdade de "realizar de novo" (Wieder-verwirklichung), de retornar novamente a uma justificação estabelecida ou verdade demonstrada (ausgewiesene Wahrheit) como "identicamente a mesma". Tal impulso científico para a generalidade coloca-nos, por sua vez, diante daquilo que, aos olhos do autor, justificaria o sentido do conhecimento: a "evidência" (Evidenz, Einsicht). Nela, a coisa intencionada não é apenas visada de forma distante ou "remota" (sachfern), como objeto de uma intenção meramente significativa. Antes disso, a coisa visada nos é, de certo modo, presente "ela própria" (sie selbst), em seu estado de coisa "ele próprio". Trata-se, portanto, do que Husserl considera um primeiro princípio metódico, destinado a reger todos os passos ulteriores: a evidência da presença da coisa à consciência.

Afinal, como lembra o autor, ao asserir predicações sobre os objetos, a ciência não quer apenas formular juízos acerca dos mesmos, mas fundá-los na evidência. Nos termos de Husserl, tal "evidência predicativa implica em uma evidência pré-predicativa" ("Prädikative Evidenz schließt vorprädikative $\left.e n^{\prime \prime}\right)^{41}$. Quer dizer, implica, em última instância, em qualquer coisa visada, respectivamente, vista evidentemente e expressa. As ciências aspiram predicações destinadas a dar à intuição pré-predicativa (das vorprädikativ Erschaute) uma expressão completa e evidentemente adequada. E é jus-

\footnotetext{
40 Segundo André Muralt:"O desenvolvimento da ciência é, por conseguinte, dependendo de como nós o vejamos, uma idealização da ciência real ou uma progressiva realização da ciência ideal". (MURALT, A. The Idea of Phenomenology: Husserlian Exemplarism. Evanston: Northwestern University Press, 1974, p. 25).

${ }^{41}$ HUSSERL, E. Cartesianische Meditationen und Pariser Vorträge. Husserliana (Band I). Den Haag, Netherlands: Martinuos Nijhoff, ([1931/ 1929] 1973), § 4, p. 52.
} 
tamente o princípio metódico da evidência que deverá reger esta tarefa. A evidência pré-predicativa supõe, por sua vez, no plano sensível, uma coisa visada, cuja presença à consciência assegura-nos a sua evidenciação. Através da evidência da coisa visada, a intenção vazia preenche-se: tem-se um "preenchimento de significação" (Bedeutungserfüllung). E é neste tal "preenchimento" (Erfüllung), que nos deparamos, então, com uma camada teleológica mais originária, inerente à vida intencional. Afinal, desde Investigações Lógicas, Husserl chama a atenção, no caso da percepção sensível, para os graus sucessivos de preenchimento intuitivo dos atos intencionais, assegurando o aclaramento gradativo do objeto visado. Se tais atos aspiram a um preenchimento intuitivo, cada grau de preenchimento aspiraria, por sua vez, a um "ideal de preenchimento definitivo" (Ideal der letzten Erfüllung), tendo como fim a "perfeição da adequação" (Vollkommenheit der Adäquation) entre $\mathrm{o}$ ato intencional significativo e seu preenchimento intuitivo ${ }^{42}$. Em tal série de preenchimentos, tratar-se-ia, portanto, de uma "teleologia de realização" ${ }^{43}$, ou ainda de uma "tendência intencional" 44

Somos, então, conduzidos de um telos espiritual que guiaria a humanidade europeia para uma teleologia mais originária, imanente às regiões espirituais, ramificadas da própria filosofia. Se a crítica ao naturalismo nos fez passar das origens da fenomenologia para o período das reflexões sobre a cultura, a análise desta teleologia oculta (imanente à humanidade europeia) nos permite fazer o movimento inverso: das reflexões sobre a crise da Europa à distinção propedêutica em fenomenologia entre "intenções de significação" (Bedeutungsintentionen) e "preenchimento de significação" (Bedeutungserfüllung). Essa é apenas uma nova linha de investigação, cuja análise nos permite regressar às origens da fenomenologia. Porém, um exame mais detalhado deste movimento inverso ficará para outra ocasião.

\section{Endereço do Autor:}

Rua da Conceição, nº 97. Centro.

Rio Bonito-RJ. Cep: 28800-000

cdctourinho@yahoo.com.br

\footnotetext{
${ }^{42}$ Husserl apresenta-nos, ao final do $\S 16$ da Sexta Investigação, um exemplo desta série ascendente de preenchimento (Steigerungsreihen der Erfüllung). O exemplo mostra-nos a passagem de um grosseiro desenho apenas esboçado para um desenho a lápis realizado com mais exatidão. Em seguida, a passagem deste desenho a lápis para uma imagem mais nítida, chegando até a realização de uma pintura com maior vividez. Por fim, a passagem para a presença do mesmo objeto, visivelmente o mesmo. Cf. TOURINHO, C. D. C. "Sobre a adequação entre intenção significativa e preenchimento intuitivo nas Investigações Lógicas de Husserl". In: Cognitio: Revista de Filosofia, p. 368.

${ }^{43}$ Cf. SHÉRER, R. La Fenomenología de las "Investigaciones Lógicas" de Husserl. Biblioteca Hispánica de Filosofía. Madrid: Editorial Gredos, 1969, p. 282-283.

${ }_{44}$ Nos termos de André Muralt: "Esta tendência teleológica é uma tendência intencional. Intencionalidade é teleologia...". (MURALT, A. The Idea of Phenomenology: Husserlian Exemplarism. Evanston: Northwestern University Press, 1974, p. 27.
} 